\title{
Application of DBNPA dosage for biofouling control in spiral wound membrane systems
}

\author{
A. Siddiquia, ${ }^{a, *}$ I. Pinel b,, E.I. Prest ${ }^{\mathrm{b}}$, Sz.S. Bucs ${ }^{\mathrm{a}}$, M.C.M. van Loosdrecht ${ }^{\mathrm{b}}$, J.C. Kruithof ${ }^{\mathrm{c}}$, \\ J.S. Vrouwenveldera, , , $\mathrm{c}$ \\ ${ }^{a}$ King Abdullah University of Science and Technology (KAUST), Water Desalination and Reuse Center (WDRC), \\ Division of Biological and Environmental Science and Engineering (BESE), Thuwal 23955-6900, Saudi Arabia, \\ email: Amber.Siddiqui@kaust.edu.sa (A.Siddiqui),Szilard.Busc@kaust.edu.sa (Sz.S.Bucs), \\ Johannes.Vrouwenvelder@kaust.edu.sa \\ ${ }^{\mathfrak{b}}$ Department of Biotechnology, Faculty of Applied Sciences, Delft University of Technology, Van der Maasweg 9, 2629 HZ Delft, \\ The Netherlands, email: I.S.M.Pinel@tudelft.nl (I.Pinel), E.I.E.D.Prest@tudelft.nl (E.I.Prest), \\ M.C.M.vanloosdrecht@tudelft.nl (M.C.M. van Loosdrecht),J.S.Vrouwenvelder@tudelft.nl (J.S. Vrouwenvelder) \\ ${ }^{c}$ Wetsus, European Centre of Excellence for Sustainable Water Technology, Oostergoweg 9, 8911 MA Leeuwarden, The Netherlands, \\ email: Joop.Kruithof@wetsus.nl (J.C. Kruithof),Hans.Vrouwenvelder@wetsus.nl (J.S.Vrouwenvelder)
}

Received 19 September 2016; Accepted 8 November 2016

\section{A B S T R A C T}

Biocides may be used to control biofouling in spiral-wound reverse osmosis (RO) and nanofiltration (NF) systems. The objective of this study was to investigate the effect of biocide 2,2-dibromo-3-nitrilopropionamide (DBNPA) dosage on biofouling control. Preventive biofouling control was studied applying a continuous dosage of substrate $(0.5 \mathrm{mg} / \mathrm{L})$ and DBNPA $(1 \mathrm{mg} / \mathrm{L})$. Curative biofouling control was studied on pre-grown biofilms, once again applying a continuous dosage of substrate $(0.5 \mathrm{mg}$ acetate $\mathrm{C} / \mathrm{L}$ ) and DBNPA ( 1 and $20 \mathrm{mg} / \mathrm{L}$ ). Biofouling studies were performed in membrane fouling simulators (MFSs) supplied with biodegradable substrate and DBNPA. The pressure drop was monitored in time and at the end of the study, the accumulated biomass in MFS was quantified by adenosine triphosphate (ATP) and total organic carbon (TOC) analysis. Continuous dosage of DBNPA $(1 \mathrm{mg} / \mathrm{L})$ prevented pressure drop increase and biofilm accumulation in the MFSs during a run time of $7 \mathrm{~d}$, showing that biofouling can be managed by preventive DBNPA dosage. For biofouled systems, continuous dosage of DBNPA ( 1 and $20 \mathrm{mg} / \mathrm{L}$ ) inactivated the accumulated biomass but did not restore the original pressure drop and did not remove the accumulated inactive cells and extracellular polymeric substances (EPS), indicating DBNPA dosage is not suitable for curative biofouling control.

Keywords: Biofouling control; Biocide DBNPA; Membranes; Water treatment; Seawater desalination; Wastewater reuse

\section{Introduction}

The use of membrane filtration processes for the production of fresh and clean water has strongly increased over the last decades. Nanofiltration (NF) and reverse osmosis $(\mathrm{RO})$ are processes removing salts, micropollutants, viruses and microorganisms, enabling the production of high quality water. The membrane lifetime and operational costs are

*Corresponding author. affected by fouling. The consequence of fouling is e.g. an increased feed pressure to maintain water production, the need to perform chemical cleanings of the membranes and eventually membrane replacement.

Four types of fouling can occur: scaling (inorganic fouling), colloid fouling, organic fouling and biofouling. Biofouling is most frequently encountered and most difficult to control. Biofouling is defined as the amount of accumulated biofilm (biomass) causing unacceptable membrane performance loss [1]. Biofouling is caused by the formation of a biofilm on the membrane and spacer surfaces on the feed 
side of the membrane. When bacteria adhere, they start to multiply and excrete an organic polymeric matrix of microbial origin called extracellular polymeric substances (EPS) which is a slimy hydrated gel [2-5]. EPS protect bacterial cells from harsh conditions such as hydraulic shear and chemical cleaning [6-8]. A biofilm evolves to adapt to the environment and is resistant to different kinds of stress making biofilm control challenging.

Several strategies have been proposed to cope with biofouling. Pre-treatment processes such as coagulation or ultraviolet irradiation [9] may help reducing or delaying biofilm accumulation. Performance of membranes and spacers modified by polydopamine, polydopamine-g-PEG or copper coatings [10] has also been studied for biofouling control, but these coatings did not prevent long-term biofilm formation. Free chlorine is known to damage the currently used polyamide RO membranes, decreasing membrane rejection properties. Membrane resistance is found to be much better using monochloramine as compared to chlorine [11,12]: 300,000 ppm-h for chloramine and up to $1000 \mathrm{ppm}-\mathrm{h}$ for free chlorine. Monochloramine is formed by adding ammonia to chlorine, which may cause the presence of small amounts of residual free chlorine. In addition, iron and manganese catalyses membrane oxidation by monochloramine $[11,13]$. Moreover monochloramine use can cause the formation of N-nitrosodimethylamine (NDMA), a potential carcinogen, with limited rejection by $\mathrm{RO}(10-50 \%)$ [14].

Chemical dosage to the feed water may enable biofouling control. Recently, an alternative for monochloramine 2,2-dibromo-3-nitrilopropionamide (DBNPA) has been applied in limited number of water treatment plants. DBNPA is also used in the pulp, paper, oil, and gas industry [15].

DBNPA is a non-oxidative agent, rapidly degrading in alkaline aqueous solutions [16]. The organic water content as well as light enhance the hydrolysis and debromination of DBNPA into cyanoacetamide followed by degradation into cyanoacetic acid and malonic acid, that are non-toxic compounds [17]. This degradation pathway makes the use of DBNPA relatively environmentally friendly. DBNPA is compatible with polyamide based membranes and shows high rejection rates for $\mathrm{RO}$ membranes [18]. The antimicrobial effect is due to the fast reaction between DBNPA and sulfur-containing organic molecules in microorganisms such as glutathione or cysteine [19-21]. The properties of microbial cell-surface components are irreversibly altered, interrupting transport of compounds across the membrane of the bacterial cell and inhibiting key biological processes of the bacteria $[19,20,22]$.

To assess the anti-biofouling effect, on-line and off-line applications of the biocide have been studied on industrial scale RO installations with a 20 ppm DBNPA concentration in the feed water. Industrial case studies described by [18] indicate a preventive effect of the biocide, but many details were not given. Only very limited information on the suitability of DBNPA to control membrane biofouling under well-defined conditions is available.

The objective of this study was to determine, under well-controlled conditions, the effect of biocide DBNPA dosage on biofouling control in membrane systems. Preventive and curative biofouling control strategies were investigated in a series of experiments with membrane fouling simulators operated in parallel, fed with feed water supplemented with DBNPA (1 or $20 \mathrm{mg} / \mathrm{L}$ ) and a biodegradable substrate sodium acetate. A higher substrate concentration in feed water has shown to result in a faster and larger pressure drop increase and a higher accumulated amount of biomass [23-26]. In the studies acetate was dosed as substrate to enhance the biofouling rate. The pressure drop was monitored and autopsies were performed to quantify the accumulated material.

\section{Material and methods}

\subsection{Experimental set-up}

In all experiments, membrane fouling simulators (MFSs) with membrane and spacer sheets dimension of $20 \mathrm{~cm}$ by $4 \mathrm{~cm}$ and $787 \mu \mathrm{m}$ channel height were applied [27]. Coupons of feed spacer and membrane can be placed in the MFS resulting in the same spatial dimensions as in spiral wound membrane elements. Six identical MFSs were operated in parallel simultaneously. The development of fouling was monitored by measuring the pressure drop increase over the feed spacer channel of the MFS and by analysis of sheets of membrane and spacer taken from the monitor for adenosine triphosphate (ATP) and total organic carbon (TOC). In addition, visual observations were made using the MFS sight window prior to membrane and spacer sampling. During operation, the MFS window was covered with a light-tight lid to prevent growth of phototrophic organisms.

The installation consisted of two cartridge filters in series (10 $\mu \mathrm{m}$ pore-size), flow controller and dosing points (for substrate and DBNPA dosage), six MFSs and a back pressure valve (Fig. 1). The MFSs were operated at a pressure of 1.70 bar to avoid degassing. The feed water flow was $16 \mathrm{~L} / \mathrm{h}$ equal to a linear flow velocity of $0.16 \mathrm{~m} / \mathrm{s}$, representative for practice [28]. The MFSs were operated in single-pass cross-flow, without permeate production.

The feed spacer used was a $31 \mathrm{mil}(787 \mu \mathrm{m})$ thick propylene diamond-shaped feed spacer, with spacer strands in a $90^{\circ}$ position and a porosity of $\sim 0.88$, most commonly applied in spiral wound NF and RO modules for water treatment in The Netherlands. The feed spacers used in the experimental studies had the same spatial orientation, diamond (i.e., 45 degrees rotated against the main flow direction) as in spiral wound membrane modules. Membranes and spacer sheets were taken from virgin spiral-wound membrane elements (Trisep TS80, USA).

\subsection{Operating conditions}

\subsubsection{Feed water}

Drinking water was produced from surface water (at treatment plant Kralingen from Water Supply Company Evides, The Netherlands) by coagulation and sedimentation followed by ozonation, dual media filtration, and granular activated carbon filtration. Chlorine dioxide $(0.1$ $\mathrm{mg} / \mathrm{L}$ ) was added at the end of the treatment and the water was collected in a reservoir before distribution. The chlorine dioxide concentration in the reservoir effluent water 


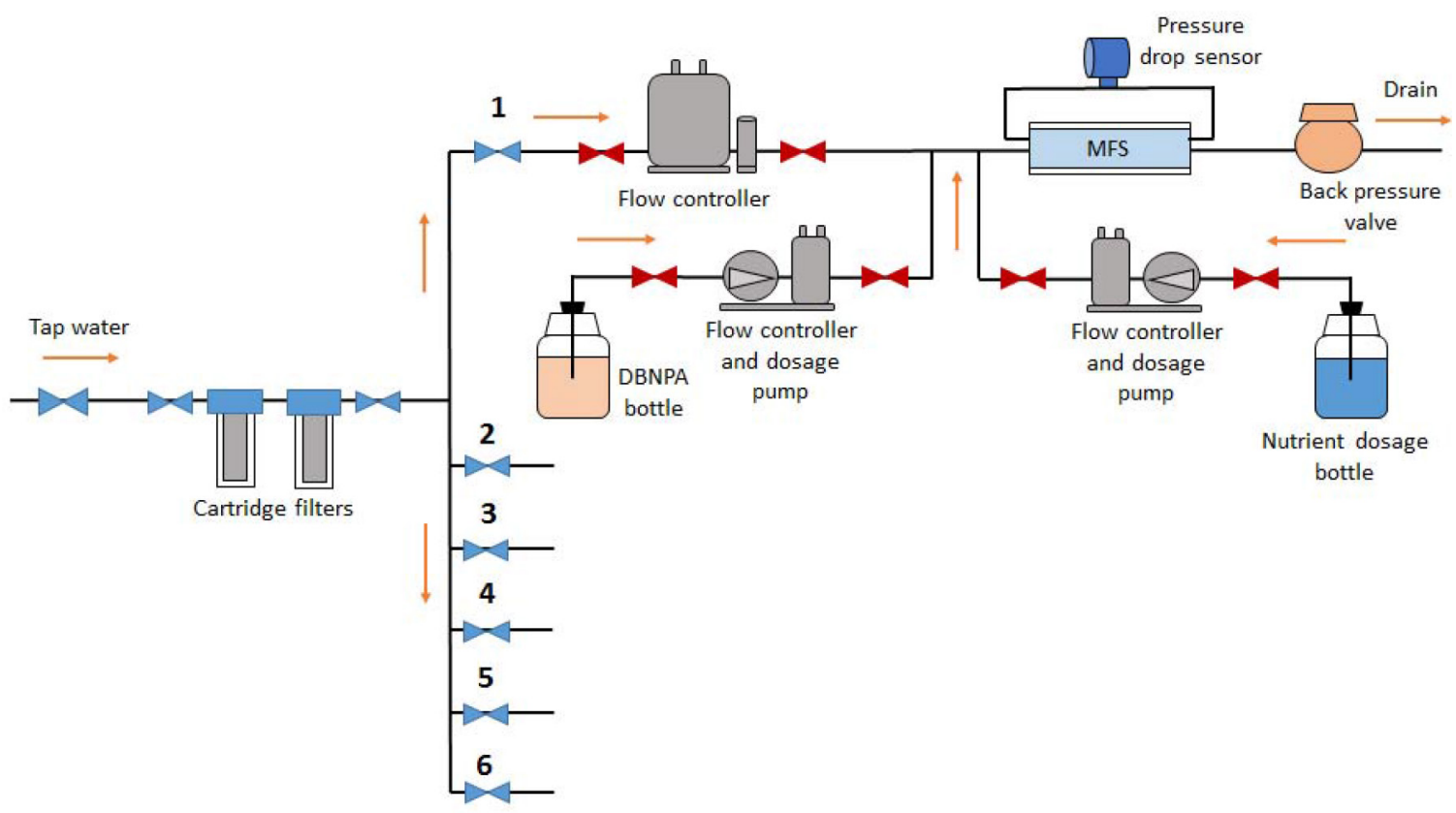

Fig. 1. Schematic diagram of an automated system for membrane fouling simulator (MFS) operation. The incoming water passes a $10 \mathrm{\mu m}$ pore-sized cartridge filter and the feed pressure is regulated using pressure dampeners and reducers. Six flow-cells installed in parallel are operated individually by a feed flow controller, a substrate and a chemical dosage pump and a back pressure valve. The pressure drop over the membrane simulator is measured with a differential pressure transmitter.

was below the detection limit. Thereafter the water was distributed in a well-maintained drinking water distribution network operated without residual disinfectant. For all MFS experiments this tap water was used as the feed water source. Microscopic investigation showed a total bacterial cell number of $2 \times 10^{5}$ cells $/ \mathrm{mL}$ in the feed water. These bacterial cell numbers were determined with epifluorescence microscopy using acridine orange as fluorochrome, applying a slightly adapted method to eliminate fading (Hobbie et al. 1977) (ASTM 1993). All fluorescing bacterial cells were counted. The number of colony forming units (CFU) on $\mathrm{R}_{2} \mathrm{~A}$ media (Reasoner's 2 agar, (Reasoner and Geldreich 1985)) was $2 \times 10^{3} \mathrm{CFU} / \mathrm{mL}$ after 10 days incubation at $25^{\circ} \mathrm{C}$.

\subsubsection{Substrate dosage}

In order to achieve a faster accumulation of biomass, substrate was dosed to the MFS feed water. The substrate solution dosed to enhance biofilm growth was composed of sodium acetate, sodium nitrate and sodium dihydrogen orthophosphate in a mass ratio C:N:P of 100:20:10, employed at different concentrations [30,31]. All chemicals were purchased in analytical grade from Boom B.V. (Meppel, The Netherlands) and were dissolved in deionized water. The $\mathrm{pH}$ value of the substrate solution was set at 11 by adding sodium hydroxide, in order to restrict bacterial growth in the substrate container of $10 \mathrm{~L}$ (supplementary material, Fig. S1). From this substrate container, a concentrated substrate solution was dosed into the feed water prior to the MFS at a flow rate of $0.05 \mathrm{~L} / \mathrm{h}$. A constant dosing was maintained using a mass flow meter (mini CoriFlow, Bronkhorst High-Tech B.V., Ruurlo, Netherlands).
The dosage of the substrate solution was checked periodically by measuring the weight of the substrate container. The dosing flow rate of the substrate solution $(0.05 \mathrm{~L} / \mathrm{h})$ to the monitor feed water was low compared to the feed water flow rate $(16.0 \mathrm{~L} / \mathrm{h}$, the reference feed flow $)$. Therefore, the high $\mathrm{pH}$-value of the substrate solution had no effect on the $\mathrm{pH}$ of the feed water of 7.8.

\subsubsection{DBNPA dosage}

DBNPA was stored at room temperature in a container protected from light. Polyethylene glycol (PEG2000, Merck, Darmstadt, USA) and demi water were used to prepare a $40 \% \mathrm{w} / \mathrm{w}$ polyethylene glycol solution. The DBNPA was diluted in the $40 \% \mathrm{w} / \mathrm{w}$ polyethylene glycol solution in $200 \mathrm{~mL}$ flasks. The flasks were covered with light tight foil to avoid DBNPA degradation by light. A constant dosage of DBNPA to the MFS feed water was maintained using a diaphragm metering pump (StepDos O8S, KNF Neuberger, USA). The flow rate of the solution $(7.5 \mathrm{~mL} / \mathrm{h})$ to the monitor feed water was low compared to the feed water flow rate $(16.0 \mathrm{~L} / \mathrm{h}$, the reference feed flow). The DBNPA dosage solution was freshly prepared every day to eliminate possible DBNPA degradation. DBNPA concentrations of 1 and 20 $\mathrm{mg} / \mathrm{L}$ in the MFS feed water were applied.

\subsection{Experimental analysis}

\subsubsection{Pressure drop evaluation}

Pressure drop measurements were performed with a pressure difference transmitter (Endress \& Hauser, type 
Deltabar S: PMD70-AAA7FKYAAA, Switzerland). The calibrated measuring range was $0-0.5$ bar [32].

\subsubsection{Biomass concentration}

All studies were carried out in parallel MFS operation. Membrane and spacer coupons from the MFSs were autopsied directly at the end of operation. Immediately after visual inspection, the membrane and spacer sheets were analysed for biomass accumulation using ATP and TOC. The same sampling methods and analyses were performed for all studies. Details of the methods have been described elsewhere [27]. ATP is applied to determine the concentration of active biomass and TOC concentration is applied to determine the total organic carbon amount of the biomass. The selection for the biomass parameters ATP and TOC was based on earlier studies by $[27,33]$ and has been applied in various studies [30,34]. In some earlier studies, after cleaning, a strong membrane performance decline caused by the accumulated material with a low ATP value and a high TOC value indicated that biomass was inactivated but not removed. Additionally performed total direct cell count analyses [35] and scanning electron microscopy (SEM-EDX) confirmed that biomass was still present and further analysis of membrane operation data showed that cleaning inactivated the biomass but did not remove it from the membrane (corresponding with the low ATP and high TOC values). Therefore, the combination of ATP and TOC analysis was applied for biomass quantification and characterization. ATP was used to characterize active biomass and TOC was applied for combined quantification of biomass and EPS.

To characterize the accumulated fouling, sections of membrane and feed spacers were taken from the MFSs. The sections $\left(16 \mathrm{~cm}^{2}\right)$ were placed in a capped tube in $20 \mathrm{~mL}$ sterile water. To determine the amount of biomass, the tubes with the membrane sections were placed in an ultrasonic cleaning bath (Bransonic, model 5510E-DTH, output $135 \mathrm{~W}$, $42 \mathrm{kHz}$ ). Low energy sonic treatment $(2 \mathrm{~min})$ followed by mixing on a vortex (few seconds) was repeated two times. When the liquid was visually not homogeneous or when all biomass was not removed from the materials, additional time-intervalled treatments were applied with a sonifier probe (Branson Sonifier 250, duty cycle $30 \%$, output control 2) for 3 to 5 min (sample kept on ice) until the liquid was homogenous. Next, water collected from the tubes was used to determine the biomass parameter ATP. The same treatment with sheets of membrane and spacer was applied with ultrapure water for TOC analysis.

\section{Results}

The development of feed channel pressure drop (FCP) during the run time and biomass concentration (ATP, TOC) in membrane fouling simulators (MFSs) at the end of the run were investigated to assess the potential of DBNPA use for preventive and curative biofouling control (Table 1). The MFS feed water was continuously supplemented with DBNPA and biodegradable substrate (Table 2). Autopsies were performed on membrane sheets and spacers taken from the MFSs to quantify the accumulated biofilm amount.
Table 1

Structure of studies performed to evaluate the effect of DBNPA dosage on biofouling control

\begin{tabular}{|c|c|c|c|c|}
\hline & $\begin{array}{l}\text { DBNPA } \\
\text { dosage } \\
(\mathrm{mg} / \mathrm{L})\end{array}$ & $\begin{array}{l}\text { Evaluation } \\
\text { based on }\end{array}$ & Section & Figure \\
\hline $\begin{array}{l}\text { Preventive } \\
\text { biofouling } \\
\text { control }\end{array}$ & 1 & $\mathrm{P}, \mathrm{V}, \mathrm{A}$. & 3.1 & Fig. 3, S2 \\
\hline $\begin{array}{l}\text { Curative } \\
\text { biofouling } \\
\text { control }\end{array}$ & & & 3.2 & \\
\hline $\begin{array}{l}\text { - Regular } \\
\text { dosage }\end{array}$ & 1 & $\mathrm{P}, \mathrm{V}, \mathrm{A}, \mathrm{T}$ & 3.2 .1 & Fig. 4, S3 \\
\hline $\begin{array}{l}\text { - High } \\
\text { dosage }\end{array}$ & 20 & $\mathrm{P}, \mathrm{V}, \mathrm{A}, \mathrm{T}$ & 3.2 .2 & Fig. 5, S4 \\
\hline
\end{tabular}

P: pressure drop change; V: visual observations of the membrane and feed spacer sheets in the MFS; A: adenosine triphosphate (ATP) measurements; T: Total Organic Carbon (TOC) measurements of the accumulated material on the membrane and feed spacer.

\subsection{Preventive biofouling control using 1 ppm DBNPA}

To assess the suitability of DBNPA dosage for preventive biofouling control, six MFSs were operated in parallel for $7 \mathrm{~d}$. Three MFSs were fed with water containing sodium acetate as biodegradable substrate $(0.5 \mathrm{mg} / \mathrm{L})$ and DBNPA $(1 \mathrm{mg} / \mathrm{L})$. As controls, one MFS was operated without dosage, one MFS was dosed with substrate only, and one MFS with DBNPA only. The feed channel pressure drop was monitored in time and after the 7-d study the accumulated biomass was quantified.

The pressure drop increased strongly with time for the MFS supplemented with substrate only, while a very restricted pressure drop increase $(\leq 10 \%)$ was found for the MFSs (i) without any dosage, (ii) with DBNPA dosage, and (iii) with substrate and DBNPA dosage (Fig. 2 A, B). After $7 \mathrm{~d}$ of operation, the MFSs were opened for analysis of the accumulated material. The MFS fed with water with only substrate addition showed a high ATP concentration $(2.0 \times$ $10^{4} \mathrm{pg}$ ATP $\left./ \mathrm{cm}^{2}\right)$, while very low ATP concentrations $(\leq 200$ pg ATP $/ \mathrm{cm}^{2}$ ) were found for the MFSs (i) without dosage, (ii) with DBNPA dosage, and (iii) with substrate and DBNPA dosage (Fig. 2C). Visual inspection of the membrane and spacer sheets in the MFSs after 7-d operation showed the presence of biofilm in the MFS fed with substrate only (Fig. S2, supplementary material), in agreement with the increased pressure drop and biomass (ATP) measurements.

Comparison of the MFSs without dosage $(-)$ and the MFS with DBNPA dosage only (D) showed no influence of the dosage of DBNPA on pressure drop increase and biofilm accumulation (Fig. 2), so DBNPA dosage was not contributing to the biofilm development. The three MFSs fed with water containing substrate and DBNPA (SD in triplicate) did not show an increase in pressure drop and biofilm accumulation, showing that continuous DBNPA dosage (1 $\mathrm{mg} / \mathrm{L}$ ) did prevent biofilm accumulation even in the presence of a high substrate concentration in the feed water (Fig. 2). Therefore, continuous DBNPA dosage with a dose of 1 $\mathrm{mg} / \mathrm{L}$ is a strategy to prevent or restrict biofouling. 
Table 2

Experimental conditions of studies to determine effect of biocide DBNPA dosage on biofouling control

\begin{tabular}{|c|c|c|c|c|c|c|c|}
\hline Study & $\begin{array}{l}\text { Monitor } \\
\text { code }\end{array}$ & $\begin{array}{l}\text { DBNPA } \\
\text { dosage } \\
\text { (mg/L) }\end{array}$ & $\begin{array}{l}\text { Substrate } \\
\text { dosage ( } \mu \mathrm{g} \\
\mathrm{C} / \mathrm{L}) \#\end{array}$ & $\begin{array}{l}\text { Start } \\
\text { dosage } \\
\text { DBNPA (d) }\end{array}$ & $\begin{array}{l}\text { Duration } \\
\text { dosage } \\
\text { DBNPA }\end{array}$ & $\begin{array}{l}\text { Autopsy } \\
\text { on day (d) }\end{array}$ & Comme \\
\hline
\end{tabular}

(d)

Prevention of biofouling

S No

- No

D $\quad 1$

SD

$\mathrm{SD}$

SD $\quad 1$

Curative biofouling control

Study 1

$\begin{array}{lll}\text { S } & \text { No } & 500 \\ \text { S1 } & \text { No } & 500 \\ \text { SD1 } & 1 & 500 \\ \text { SD2 } & 1 & 500 \\ \text { SD3 } & 1 & 500 \\ \text { SD5 } & 1 & 500\end{array}$

Curative biofouling control

Study 2

\begin{tabular}{|c|c|c|c|c|c|c|}
\hline S & No & 200 & n.a. & n.a. & 7 & Positive control: biofouling expected \\
\hline S1 & No & 200 & n.a. & n.a. & 5 & Biofilm amount at start DBNPA dosage \\
\hline SD5 & 20 & 200 & 5 & 5 & 10 & Impact DBNPA (triplicate experiment) \\
\hline SD5 & 20 & 200 & 5 & 5 & 10 & Impact DBNPA (triplicate experiment) \\
\hline SD5 & 20 & 200 & 5 & 5 & 10 & Impact DBNPA (triplicate experiment) \\
\hline D10 & 20 & No & 5 & 5 & 10 & $\begin{array}{l}\text { Negative control: no biofouling } \\
\text { expected }\end{array}$ \\
\hline
\end{tabular}

\#: substrate dosage always started on day 0, when applied. n.a.: not applicable. No: dosage not applied.

\subsection{Curative biofouling control}

To address the suitability of DBNPA dosage to cure a membrane system suffering from biofouling, experiments were carried out with pre-grown biofilms in MFSs causing a pressure drop increase $(\geq 60 \%)$. After starting continuous dosage of DBNPA, further development in time of the pressure drop and biomass amount (ATP, TOC) were monitored (Figs. 3 and 4). Curative biofouling control was studied applying a continuous dosage of $1 \mathrm{mg} / \mathrm{L}$ DBNPA (3.2.1) and $20 \mathrm{mg} / \mathrm{L}$ DBNPA (3.2.2).

\subsubsection{Curative biofouling control using 1 ppm DBNPA}

Six MFSs were operated in parallel. Five MFSs were operated with substrate dosage only $(0.5 \mathrm{mg} / \mathrm{L})$ for four days to develop a biofilm causing a pressure drop increase. One MFS (S1) was operated for four days only (until the start of DBNPA dosage) to quantify the accumulated bio- mass prior to the start of DBNPA dosage. Subsequently, four MFSs were operated with an additional dosage of DBNPA $(1 \mathrm{mg} / \mathrm{L})$. To evaluate the effect of DBNPA dosage on the pre-grown biomass, MFSs were opened for accumulated biomass analysis after various run times with DBNPA dosage (1, 2, 3 and 5.5 d: SD1, SD2, SD3 and SD5). As control, one MFS was operated with substrate dosage only (S) until the end of the run.

The pressure drop increased strongly in all MFSs during the first four days with only substrate dosage (Fig. 3A). Starting day four, continuous additional dosage of $1 \mathrm{mg} / \mathrm{L}$ DBNPA (i) inactivated the accumulated biomass (Fig. 3C), but (ii) did not restore the original pressure drop (Fig. 3A, B), and (iii) did not remove the accumulated inactivated cells and EPS (Fig. 3D). Comparison of the control with substrate dosage only (S) to experiments with additional DBNPA dosage (SD1, SD2, SD3 and SD5) showed that DBNPA dosage prevented (i) a further increase of pressure drop (Fig. 3B) and (ii) a further increase of bacterial cells 

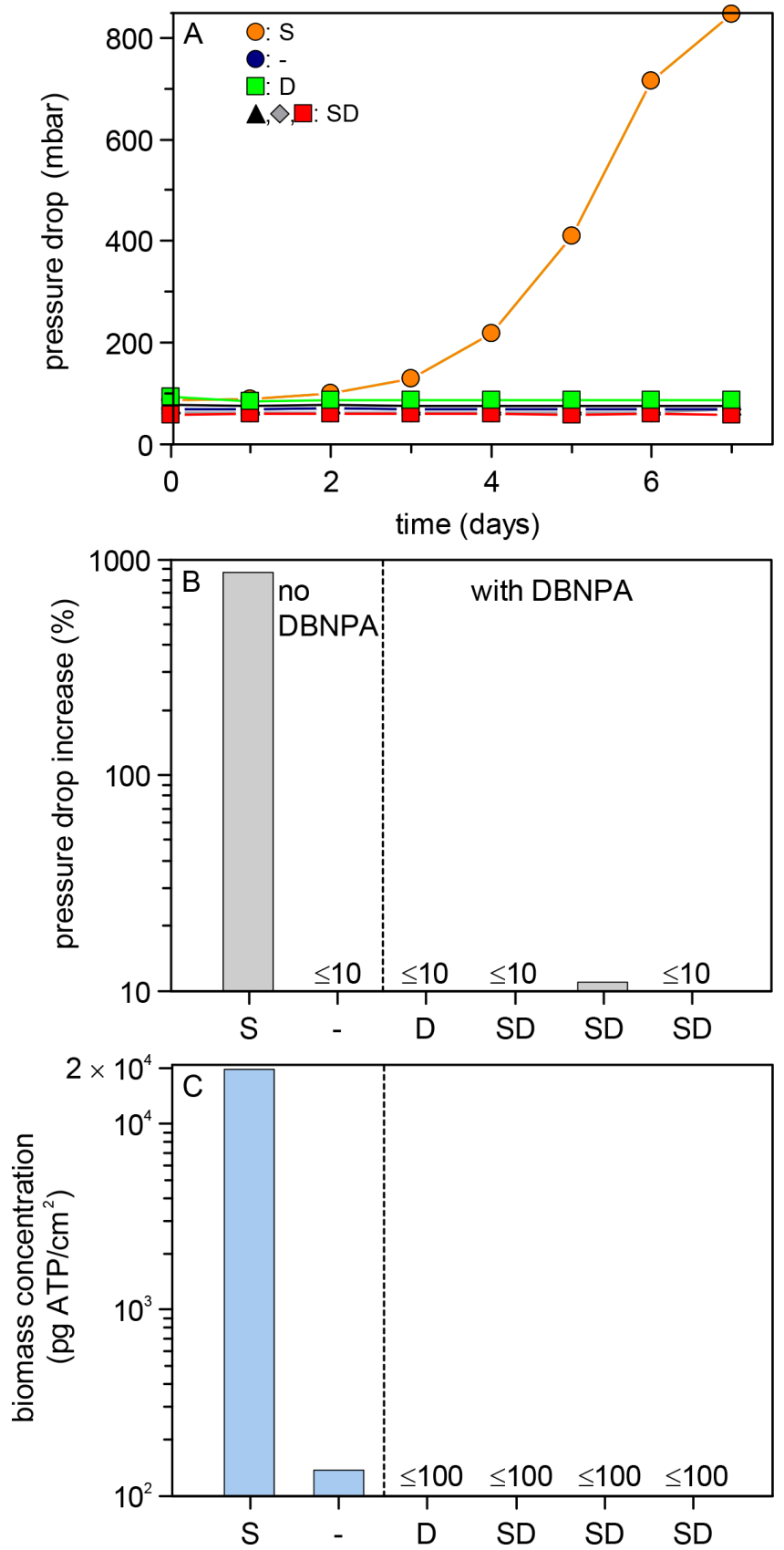

Fig. 2. DBNPA dosage $(1 \mathrm{mg} / \mathrm{L})$ to prevent biofouling. Pressure drop in time (A), pressure drop increase (B) and accumulated biomass concentration ATP (C) in MFSs. Feed water of all MFSs (except - and D) was supplemented with biodegradable substrate $(500 \mu \mathrm{g} \mathrm{C} / \mathrm{L})$ from day 0 . DBNPA was continuously dosed to the feed water (1 mg DBNPA/L) of all MFSs except - and S. $\mathrm{S}, \mathrm{D}$ and - are controls. Continuous dosage of DBNPA to feed water $(1 \mathrm{mg} / \mathrm{L})$ is effective for preventive biofouling control.

and EPS (Fig. 3D). With increasing time of DBNPA dosage (from 1.0 to $5.5 \mathrm{~d}$ ) no biomass removal was found, but continuous dosage of $1 \mathrm{mg} / \mathrm{L}$ DBNPA successfully prevented further build-up of biofouling in a fouled membrane simulator (Fig. 3C). Continuous DBNPA dosage (1 mg/L) was not suitable for curative biofouling control, since the existing biofilm was not removed and the original pressure drop not restored.

\subsubsection{Curative biofouling control using 20 ppm DBNPA}

Applying $1 \mathrm{mg} / \mathrm{L}$ DBNPA did not reinstate the initial pressure drop, so was not applicable for curative biofouling control. Therefore, experiments were carried out with a much higher continuous dosage of $20 \mathrm{mg}$ /L DBNPA (Table 2). Three MFSs were dosed with substrate and DBNPA (SD5 in triplicate). As controls, two MFSs were operated with substrate dosage only (S and S1) and one MFS with DBNPA dosage only (D10). DBNPA dosage only (D10) caused no pressure drop increase and no biofilm accumulation (Fig. 4 ), confirming that DBNPA dosage was not contributing to biofilm development and pressure drop increase, not even for a very high DBNPA dosage.

The results of dosing $20 \mathrm{mg} / \mathrm{L}$ DBNPA are consistent with the results of the $1 \mathrm{mg} / \mathrm{L} \mathrm{DBNPA}$ dosage study (3.2.1). The pressure drop increased strongly in all MFSs during the first $5 \mathrm{~d}$ with only substrate dosage (Fig. 4A). Continuous additional dosage of $20 \mathrm{mg} / \mathrm{L}$ DBNPA starting day five for a period of five days (i) inactivated the accumulated biomass (Fig. 4C), but (ii) did not restore the original pressure drop (Fig. 4A, B) and (iii) did not remove the accumulated biomass and EPS (Fig. 4D). Comparison of the control with substrate dosage only (S for $5 \mathrm{~d}$ and $\mathrm{S} 1$ for $7 \mathrm{~d}$ respectively) with additional DBNPA dosage (SD5 in triplicate, for 10 d), showed that the DBNPA dosage prevented (i) a further increase of pressure drop (Fig. 4B) and (ii) a further increase of biomass and EPS accumulation (Fig. 4D). Just like a continuous dosage of $1 \mathrm{mg} / \mathrm{L}$ DBNPA, continuous dosage of $20 \mathrm{mg} / \mathrm{L}$ DBNPA was successful in inactivating the accumulated active biomass and preventing (further) biofilm growth (Fig 4C), but was not suitable for curative biofouling control.

\section{Discussion}

The objective of the study was to determine, under well-controlled conditions, the applicability of the biocide DBNPA for preventive and curative biofouling control in membrane systems. The preventive study showed that low DBNPA dosage (1 mg/L) avoided a pressure drop increase and biofilm accumulation in the MFS (Fig. 2). The curative study with a pre-grown biofilm showed that further EPS accumulation and pressure drop increase were avoided by DBNPA dosage of 1 and $20 \mathrm{mg} / \mathrm{L}$, but the initial pressure drop was not restored. ATP measurements show that the active biomass was inactivated, while TOC and pressure drop data showed that removal of the existing biofilm did not occur (Figs. 3 and 4). The outcomes of this study show that continuous DBNPA dosage of $1 \mathrm{mg} / \mathrm{L}$ can prevent biofouling, but the biocide does not have a curative effect for DBNPA concentrations up to $20 \mathrm{mg} / \mathrm{L}$.

\subsection{Evaluation of DBNPA dosage for biofouling control}

Boorsma et al. and Majamaa et. al independently, applied DBNPA in the feed water of integrated membrane systems to evaluate the impact on pressure drop increase 

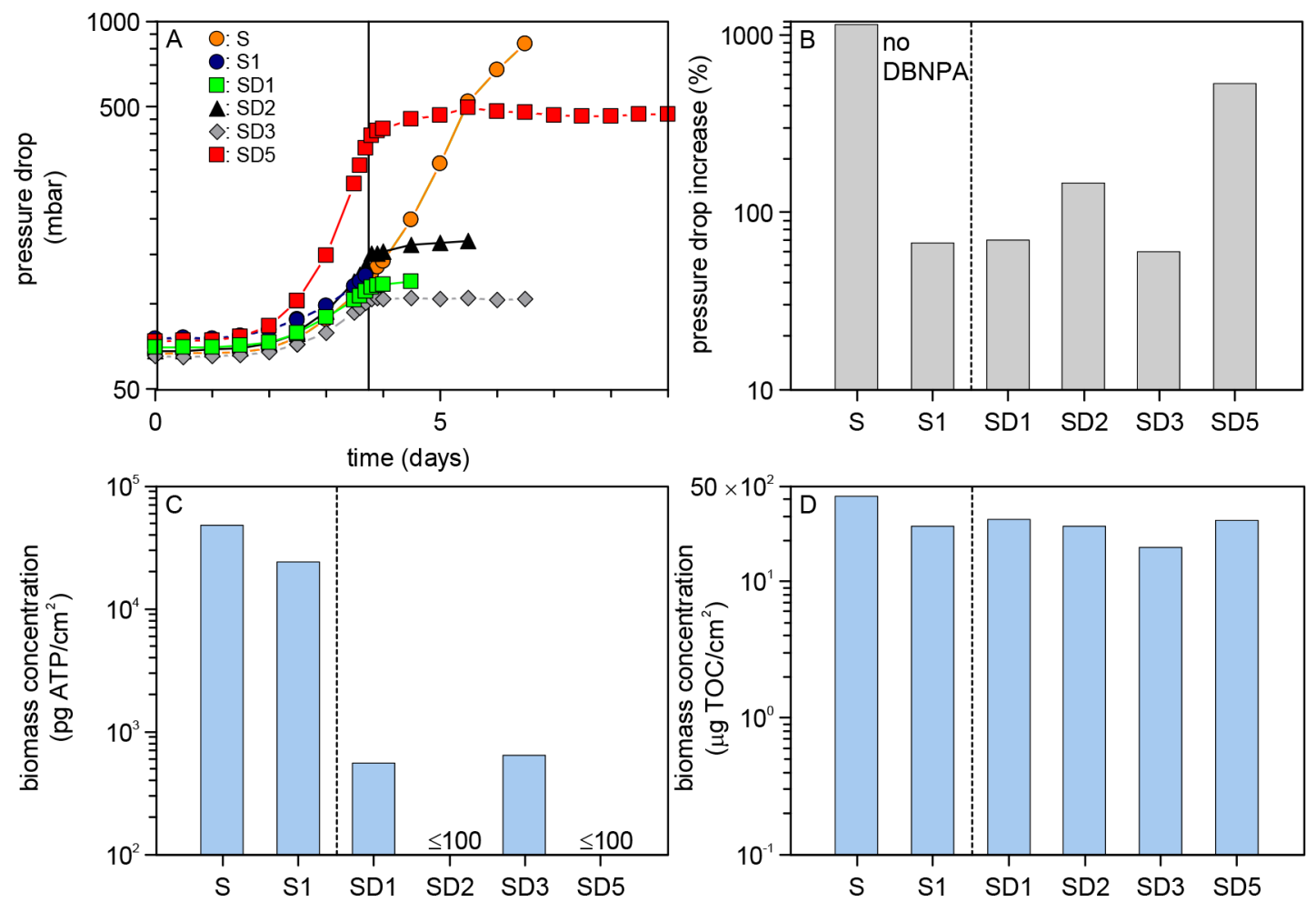

Fig. 3. DBNPA dosage (1 mg/L) to cure a biofouled membrane system. Pressure drop in time (A), pressure drop increase (B) and accumulated biomass concentration ATP (C) and TOC (D) in MFSs. Feed water of all MFSs was supplemented with biodegradable substrate $(500 \mu \mathrm{g} \mathrm{C} / \mathrm{L})$ from day 0. DBNPA was continuously dosed to the feed water (1 mg DBNPA/L) of MFSs from day 4 (vertical line in A) for 1, 2, 3 and $5.5 \mathrm{~d}(\mathrm{SD} 1, \mathrm{SD} 2, \mathrm{SD} 3, \mathrm{SD} 5)$. $\mathrm{S}$ and $\mathrm{S} 1$ are controls. DBNPA dosage $(1 \mathrm{mg} / \mathrm{L})$ is not effective for curative biofouling control.
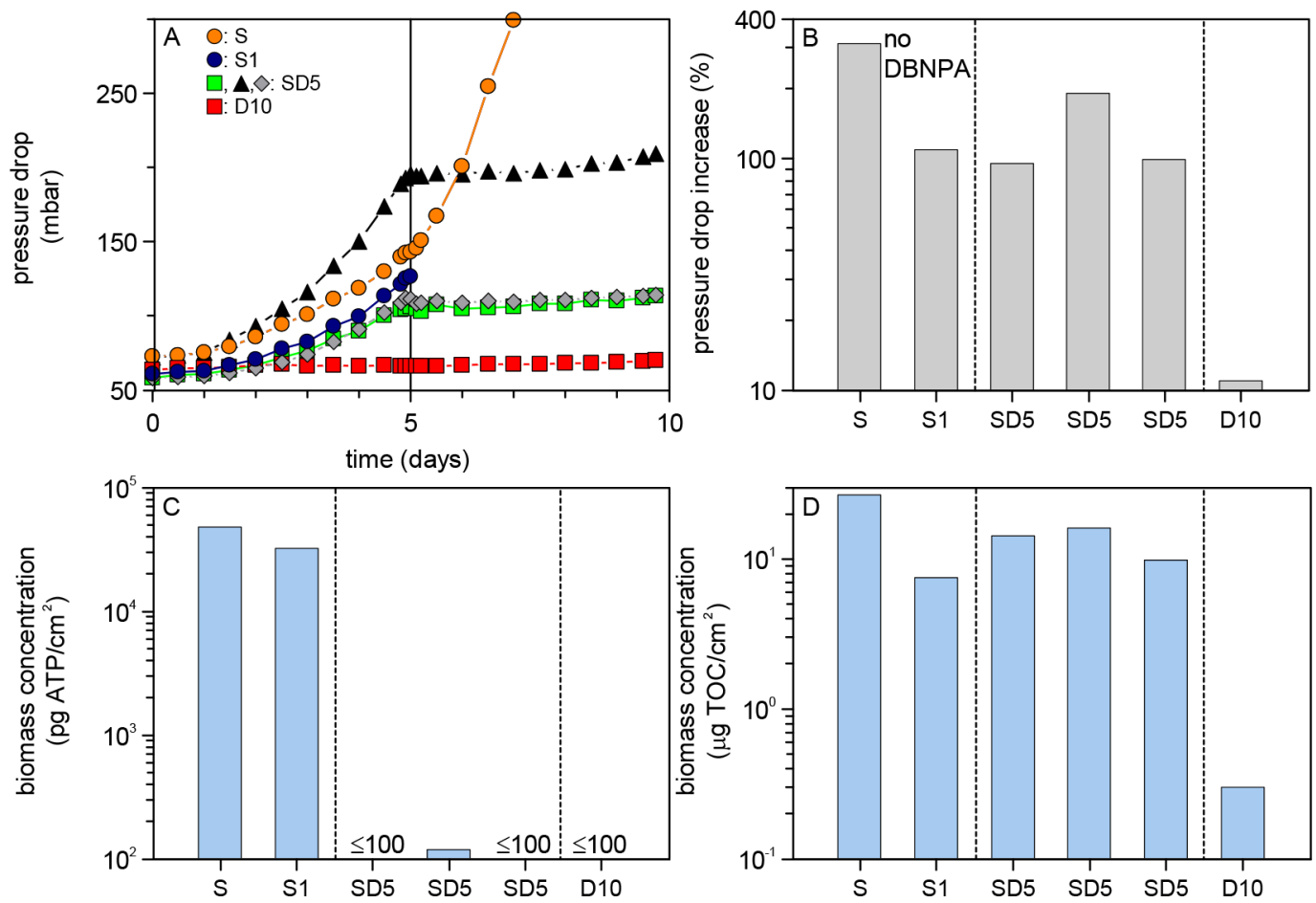

Fig. 4. DBNPA dosage (20 mg/L) to cure a biofouled membrane system. Pressure drop in time (A), pressure drop increase (B) and accumulated biomass concentration ATP (C) and TOC (D) in MFSs. Feed water of all MFSs was supplemented with biodegradable substrate (200 $\mu \mathrm{g} \mathrm{C/L}$ ) from day 0. DBNPA was continuously dosed to the feed water (20 mg DBNPA/L) of MFSs from day 5 (SD5). $\mathrm{S}, \mathrm{S} 1$ and D10 are controls. Continuous DBNPA dosage $(20 \mathrm{mg} / \mathrm{L})$ is not effective for curative biofouling control. 
and chemical cleaning frequency [36,37]. A continuous high DBNPA dosage of $20 \mathrm{mg} / \mathrm{L}$ on fouled membranes caused a significant decrease in cleaning frequency due to the stabilization of the pressure drop. This is consistent with the findings in our study (Figs. 2-5 and Fig. S5 in supplementary material). The rejection of DBNPA by membranes has already been studied on industrial scale modules [18]. A few papers mention the use of on-line shock dosages of the biocide [36] but limited information is provided on the efficiency of this application. As continuous dosage of 20 $\mathrm{mg} / \mathrm{L}$ of DBNPA did not remove the pre-grown biofilm in the MFS, no curative effect on the existing biofilm may be expected by applying shock dosages with the same DBNPA concentration. Continuous DBNPA dosage to a biofouled membrane system stopped the biofilm accumulation and stopped a further increase of pressure drop (Fig. 4). In other words, continuous DBNPA dosage stabilised but did not improve the performance of a biofouled membrane system. This stabilisation provides plant operators time to identify and address the cause of biofouling such as e.g. algal bloom [38,39], dosing an impure batch of acid [40], or anti-scalant $[27,41,42]$, while avoiding heavier biofouling.

\subsection{Outlook}

Continuous dosage of DBNPA at concentrations lower than $1 \mathrm{mg} / \mathrm{L}$ could be tested for assessment of preventive anti-biofouling action. Dosage of $1 \mathrm{mg} / \mathrm{L}$ has shown to be effective, but for full scale application the lowest efficient DBNPA dosage should be found for optimising the economy of dosing. Long-term effects of the DBNPA dosage should be assessed in full scale membrane systems. Shock dosage may be suitable for preventive biofouling control. Shock dosage of DBNPA (varying e.g. DBNPA concentration, dosage time and dosage frequency) could be tested in the MFS to evaluate the preventive anti-biofouling action. Reduction of chemical use and cost savings may be achieved compared to continuous DBNPA dosage [18].

To evaluate the potential of DBNPA dosage for preventive biofouling control, MFS with permeate production operating at high pressure are being developed. Although the absence of permeate production has no influence on the biofilm growth on the RO and NF membranes and feed spacers $[29,31]$, the effect of chemical dosage on the permeate quality is relevant to study. Results of such studies provide useful information on the expected permeate characteristics produced under practical conditions i.e. conditions used in a seawater desalination or water recovery at a wastewater treatment plant.

For a biofouled membrane system, DBNPA dosage inactivated but did not remove the biomass and did not eliminate the pressure drop increase (Figs. 3 and 4). A membrane system containing inactivated biomass and EPS still had the same feed channel pressure drop. Dreszer et al. reported that the hydraulic biofilm resistance was predominantly caused by EPS [43]. The impact of biofilm EPS on membrane performance is influenced by membrane operational parameters such as permeate flux [44-47]. Treatment achieving effective EPS removal would provide biofouling control, underlining the importance to study strategies for EPS removal from spiral wound membrane systems.

\section{Conclusions}

The lab-scale study on the influence of biocide 2,2-dibromo-3-nitrilopropionamide (DBNPA) dosage for preventive and curative biofouling control in spiral wound reverse osmosis membrane systems using membrane fouling simulators led to the following conclusions:

- Prevention of biofilm accumulation and related pressure drop increase was achieved with continuous 1 $\mathrm{mg} / \mathrm{L}$ DBNPA dosage, even when the feed water contained a high biodegradable substrate concentration (high biofouling potential).

- Curative biofouling control was not achieved by continuous 1 and $20 \mathrm{mg} / \mathrm{L}$ DBNPA dosage. Dosage of DBNPA to a biofouled membrane system (i) inactivated the accumulated biomass but (ii) did not restore the original pressure drop, and (iii) did not remove the accumulated bacterial cells and extracellular polymeric substances (EPS).

- Continuous DBNPA dosage to a biofouled membrane system prevented a further biofilm accumulation and pressure drop increase. In other words, in a biofouled membrane system the fouling was stabilized by continuous DBNPA dosage.

\section{Acknowledgements}

The research reported in this publication was supported by funding from King Abdullah University of Science and Technology (KAUST) and Evides Industriewater. Dow Chemical is acknowledged for providing the DBNPA.

\section{References}

[1] H.-C. Flemming, Biofouling in water systems-cases, causes and countermeasures., Appl. Microbiol. Biotechnol., 59 (2002) 629-640.

[2] G.G. Geesey, Microbial exopolymers: Ecological and economic considerations, ASM Am. Soc. Microbiol. News, 48(1) (1982) 9-14.

[3] D.G. Allison, I.W. Sutherland, A staining technique for attached bacteria and its correlation to extracellular carbohydrate production, J. Microbiol. Methods, 2 (1984) 93-99.

[4] H. Flemming, J. Wingender, The biofilm matrix, Nat. Rev. Microbiol., 8 (2010) 623-633.

[5] H. Lappin-Scott, S. Burton, P. Stoodley, Revealing a world of biofilms - the pioneering research of Bill Costerton., Nat. Rev. Microbiol., (2014) 1-7. doi:10.1038/nrmicro3343.

[6] A. Bridier, R. Briandet, V. Thomas, F. Dubois-Brissonnet, Resistance of bacterial biofilms to disinfectants: a review, Biofouling, 27 (2011) 1017-1032.

[7] J.W. Costerton, P.S. Stewart, E.P. Greenberg, Bacterial biofilms: a common cause of persistent infections., Science, (80) 284 (1999) 1318-1322.

[8] L. Hall-Stoodley, J.W. Costerton, P. Stoodley, M. State, B. Engineering, Bacterial biofilms: from the natural environment to infectious diseases., Nat. Rev. Microbiol, 2 (2004) 95-108.

[9] T. Harif, H. Elifantz, E. Margalit, M. Herzberg, T. Lichia, D. Minz, The effect of UV pre-treatment on biofouling of BWRO membranes: A field study, Desal. Water Treat., 31 (2011) 151-163.

[10] P.A. Araújo, D.J. Miller, P.B. Correia, M.C.M. van Loosdrecht, J.C. Kruithof, B.D. Freeman, D.R. Paul, J.S. Vrouwenvelder, Impact of feed spacer and membrane modification by hydrophilic, bactericidal and biocidal coating on biofouling control, Desalination, 295 (2012) 1-10. 
[11] M.K. da Silva, I.C. Tessaro, K. Wada, Investigation of oxidative degradation of polyamide reverse osmosis membranes by monochloramine solutions, J. Membr. Sci., 282 (2006) 375-382.

[12] S.-K. Hong, R. Reiss, J.S. Taylor, S. Beverly, Effect of feed monochloramination on performance of RO membranes, J. Korean Soc. Water Wastewater, 19 (2005) 312-317.

[13] C.J. Gabelich, J.C. Frankin, F.W. Gerringer, K.P. Ishida, I.H. Suffet, Enhanced oxidation of polyamide membranes using monochloramine and ferrous iron, J. Membr. Sci., 258 (2005) 64-70.

[14] J.S. Vrouwenvelder, J.C. Kruithof, M.C.M. van Loosdrecht, eds., Biofouling of Spiral Wound Membrane Systems, IWA Publishing, 2011.

[15] DOW, 2,2-Dibromo-3-Nitrilopropionamide (DBNPA), (2013). www.dow.com/webapps/include/GetDoc.aspx?filepath= productsafety/pdfs/noreg/233-00454.pdf\&pdf=true.

[16] EPA, 2,2-dibromo-3-nitrilopropionamide (DBNPA), 1994 https: / / www.google.nl/url? sa $=t \& r c t=j \& q=\&$ esrc $=s \&-$ source $=$ web \&cd $=1 \&$ ved $=0$ ahUKEwjorLrPmrvNAhXnYZoKHS5vDroQFggeMAA\&url=https $\% 3 \mathrm{~A} \% 2 \mathrm{~F} \% 2$ Farchive. epa.gov $\% 2$ Fpesticides $\% 2$ Freregistration $\% 2 F w e b \% 2 F p d f \% 2 F-$ 3056fact.pdf\&usg=AFQjCNHEp0oJI2Kc9vmyzQ730s3YXC 4 e9 A\&sig2=SYtVB8vlcw A_72M8kwa AZA\&bvm=bv.125221236, d.bGs\&cad=rja.

[17] F.A. Blanchard, S.J. Gonsior, D.L. Hopkins, 2,2-Dibromo3-nitrilopropionamide (DBNPA) chemical degradation in natural waters: Experimental evaluation and modeling of competitive pathways, Water Res., 21 (1987) 801-807.

[18] U. Bertheas, K. Majamaa, A. Arzu, R. Pahnke, Use of DBNPA to control biofouling in RO systems, Desal. Water Treat., 3 (2009) 175-178.

[19] M. Chervenak, A. Eachus, B. Henry, Biocide resolves bacterial hygiene, Eur. Coatings J., (2004) 26-34.

[20] W. Paulus, Directory of Microbicides for the Protection of Materials: A Handbook, Springer Science \& Business Media, 2005.

[21] S. Ullah, Biocides in papermaking chemistry, University of Jyväskylä, 2011.

[22] J. Walter, W. Richard, Mills, F. Jack, A.G. Relenyi, Compatibility of DBNPA with chlorine as water treatment biocides, in: Int. Water Conf. 46th Annu. Meet., Engineers' Soc of Western Pennsylvania, Pittsburgh, PA, USA, Pittsburgh, 1985: pp. 434-443.

[23] D.J. Miller, P. Araújo, P.B. Correia, M.M. Ramsey, J.C. Kruithof, M.C.M. van Loosdrecht, B.D. Freeman, D.R. Paul M. Whiteley, J.S. Vrouwenvelder, Short-term adhesion and long-term biofouling testing of polydopamine and poly(ethylene glycol) surface modifications of membranes and feed spacers for biofouling control., Water Res., 46 (2012) 3737-3753.

[24] R.V. Linares, S.S. Bucs, Z. Li, M. AbuGhdeeb, G. Amy, J.S. Vrouwenvelder, Impact of spacer thickness on biofouling in forward osmosis., Water Res., 57 (2014) 223-233.

[25] A. Siddiqui, N. Farhat, S.S. Bucs, R.V. Linares, C. Picioreanu, J.C. Kruithof, M.C.M. Van Loosdrecht, J. Kidwell, J.S. Vrouwenvelder, Development and characterization of 3D-printed feed spacers for spiral wound membrane systems, Water Res., 91 (2016) 55-67.

[26] S.A. Creber, J.S. Vrouwenvelder, M.C.M. van Loosdrecht, M.L. Johns, Chemical cleaning of biofouling in reverse osmosis membranes evaluated using magnetic resonance imaging, J. Membr. Sci., 362 (2010) 202-210.

[27] J.S. Vrouwenvelder, S.A. Manolarakis, J.P. van der Hoek, J.A.M. van Paassen, W.G.J. van der Meer, J.M.C. van Agtmaal, H.D.M. Prummel, J.C. Kruithof, M.C.M. van Loosdrecht, Quantitative biofouling diagnosis in full scale nanofiltration and reverse osmosis installations, Water Res., 42 (2008) 4856-4868.

[28] J.S. Vrouwenvelder, C. Hinrichs, W.G.J. van der Meer, M.C.M. van Loosdrecht, J.C. Kruithof, Pressure drop increase by biofilm accumulation in spiral wound $\mathrm{RO}$ and NF membrane systems: role of substrate concentration, flow velocity, substrate load and flow direction., Biofouling, 25 (2009) 543-555.
[29] P.A. Araújo, J.C. Kruithof, M.C.M. Van Loosdrecht, J.S. Vrouwenvelder, The potential of standard and modified feed spacers for biofouling control, J. Membr. Sci., 403-404 (2012) $58-70$.

[30] J.S. Vrouwenvelder, D.A. Graf von der Schulenburg, J.C. Kruithof, M.L. Johns, M.C.M. van Loosdrecht, Biofouling of spiral-wound nanofiltration and reverse osmosis membranes: A feed spacer problem, Water Res., 43 (2009) 583-594.

[31] J.S. Vrouwenvelder, J.A.M. van Paassen, J.C. Kruithof, M.C.M. van Loosdrecht, Sensitive pressure drop measurements of individual lead membrane elements for accurate early biofouling detection, J. Membr. Sci., 338 (2009) 92-99.

[32] O. Holm-Hansen, C.R. Booth, The measurement of adenosine triphosphate in the ocean and its ecological significance, Am. Soc. Limnol. Oceanogr., 11 (1966) 510-519.

[33] F. Beyer, B.M. Rietman, A. Zwijnenburg, P. van den Brink, J.S. Vrouwenvelder, M. Jarzembowska, J. Laurinonyte, A.J.M. Stams, C.M. Plugge, Long-term performance and fouling analysis of full-scale direct nanofiltration (NF) installations treating anoxic groundwater, J. Membr. Sci., 468 (2014) 339348.

[34] J.E. Hobbie, R.J. Daley, S. Jasper, Use of nuclepore filters for counting bacteria by fluorescence microscopy, Appl. Environ. Microbiol., 33 (1977) 1225-1228.

[35] K. Majamaa, J.E. Johnson, U. Bertheas, Three steps to control biofouling in reverse osmosis systems, Desal. Water Treat., 42 (2012) 107-116.

[36] M.J.J. Boorsma, S. Dost, S. Klinkhamer, J.C.C. Schippers, Monitoring and controlling biofouling in an integrated membrane system, Desal. Water Treat., 31 (2011) 347-353.

[37] D.A. Caron, M.È. Garneau, E. Seubert, M.D.A. Howard, L. Darjany, A. Schnetzer, I. Cetinić, G. Filteau, P. Lauri, B. Jones, Harmful algae and their potential impacts on desalination operations off southern California, Water Res., 44 (2010) 385416.

[38] L. Villacorte, Algal Blooms and Membrane Based Desalination Technology, 2014.[publisher??]

[39] J.S. Vrouwenvelder, J.A.M. van Paassen, H.C. Folmer, J.A.M.H. Hofman, M.M. Nederlof, D. van der Kooij, Biofouling of membranes for drinking water production, Water Supply, 118 (1998) 225-234.

[40] J.P. van der Hoek, J.A.M.H. Hofman, P.A.C. Bonné, M.M. Nederlof, H.S. Vrouwenvelder, RO treatment: selection of a pretreatment scheme based on fouling characteristics and operating conditions based on environmental impact, Desalination, 127 (2000) 89-101.

[41] J.S. Vrouwenvelder, S.A. Manolarakis, H.R. Veenendaal, D. van der Kooij, Biofouling potential of chemicals used for scale control in RO and NF membranes, Desalination, 132 (2000) $1-10$.

[42] C. Dreszer, J.S. Vrouwenvelder, A.H. Paulitsch-Fuchs, A. Zwijnenburg, J.C. Kruithof, H.C. Flemming, Hydraulic resistance of biofilms, J. Membr. Sci., 429 (2013) 436-447.

[43] L.A. Bereschenko, H. Prummel, G.J.. Euverink, A.J. Stams, M.C. van Loosdrecht, Effect of conventional chemical treatment on the microbial population in a biofouling layer of reverse osmosis systems, Water Res., 45 (2011) 405-416.

[44] C. Dreszer, H.C. Flemming, A. Zwijnenburg, J.C. Kruithof, J.S. Vrouwenvelder, Impact of biofilm accumulation on transmembrane and feed channel pressure drop: Effects of crossflow velocity, feed spacer and biodegradable nutrient, Water Res., 50 (2014) 200-211.

[45] R.V. Linares, A.D. Wexler, S.S. Bucs, C. Dreszer, A. Zwijnenburg, H.-C. Flemming, J.C. Kruithof, J.S. Vrouwenvelder, Compaction and relaxation of biofilms, Desal. Water Treat., 57(28) (2016) 12902-12914.

[46] T. Nguyen, F.A. Roddick, L. Fan, Biofouling of water treatment membranes: A review of the underlying causes, monitoring techniques and control measures, Membranes (Basel), 2 (2012) 804-840. 


\title{
Supplementary material
}

\section{Application of DBNPA dosage for biofouling control in spiral wound membrane systems}

\author{
A. Siddiqui, I. Pinel, E.I. Prest, Sz.S. Bucs, M.C.M. van Loosdrecht, J.C. Kruithof, \\ J.S. Vrouwenvelder
}

\section{Determining the extent of bacterial growth in the substrate storage bottle with time}

Added to a $20 \mathrm{~L}$ bottle was $2.7637 \mathrm{~g} \mathrm{CH}_{3} \mathrm{COONa} \cdot 3 \mathrm{H}_{2} \mathrm{O}, 0.5922 \mathrm{~g} \mathrm{NaNO}_{3^{\prime}} 0.2483 \mathrm{~g} \mathrm{NaH}_{2} \mathrm{PO}_{4} \cdot 2 \mathrm{H}_{2} \mathrm{O}$, and water to a volume of $20 \mathrm{~L}$ and by dosage of $1 \mathrm{M} \mathrm{NaOH}$ the $\mathrm{pH}$ was set to 11 . The added biodegradable carbon concentration in the vessel was $24 \mathrm{mg} \mathrm{C} / \mathrm{L} .1 \mu \mathrm{g} \mathrm{C} / \mathrm{L}$ supports growth of bacteria up to $10^{7}$ bacterial cells per mL.

Bottles were made in triplicate and stored at room temperature $\left(20^{\circ} \mathrm{C}\right)$ for $38 \mathrm{~d}$. Periodically over the 38 - $\mathrm{d}$ period, samples were taken from the liquid in the bottles and analysed total bacterial cell number and active biomass (ATP) concentration.

Throughout the 38-d incubation period, (i) the ATP concentrations were below the detection limit of the method $(<1 \mathrm{ng}$ ATP/L, Fig. S1) and the total bacterial cell counts were in the order of the detection limit $(1 \mathrm{cell} / \mu \mathrm{L})$ of the flow cytometric method, about 1 to 10 bacterial cells per $\mu \mathrm{L}$. No increase in ATP concentration or total bacterial cell number with time was found for the three bottles, indicating that bacterial growth in the substrate bottle solution was very limited or not occurring during storage up to $38 \mathrm{~d}$.

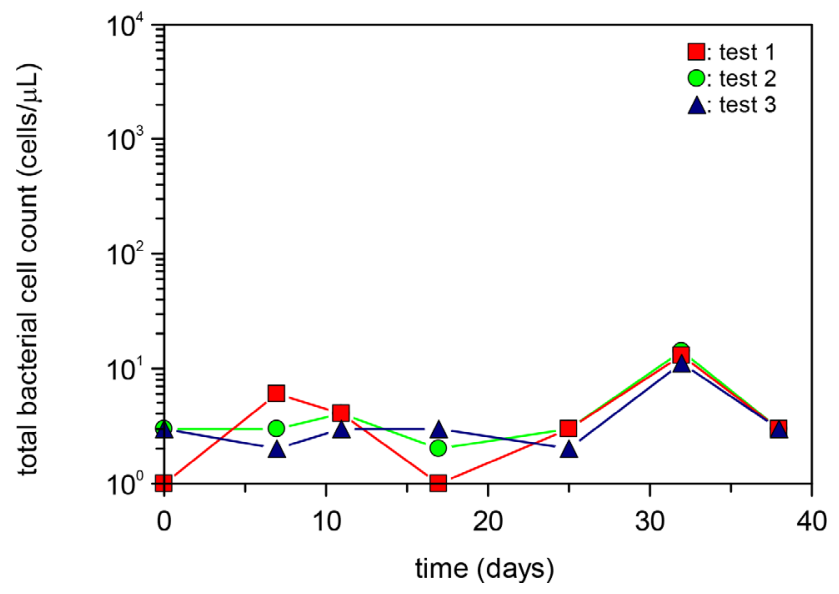

Fig. S1. Total bacterial cell count in substrate storage bottle. Total bacterial cell count (cells $/ \mu \mathrm{L})$ in the substrate storage bottle during 38-d incubation at room temperature.

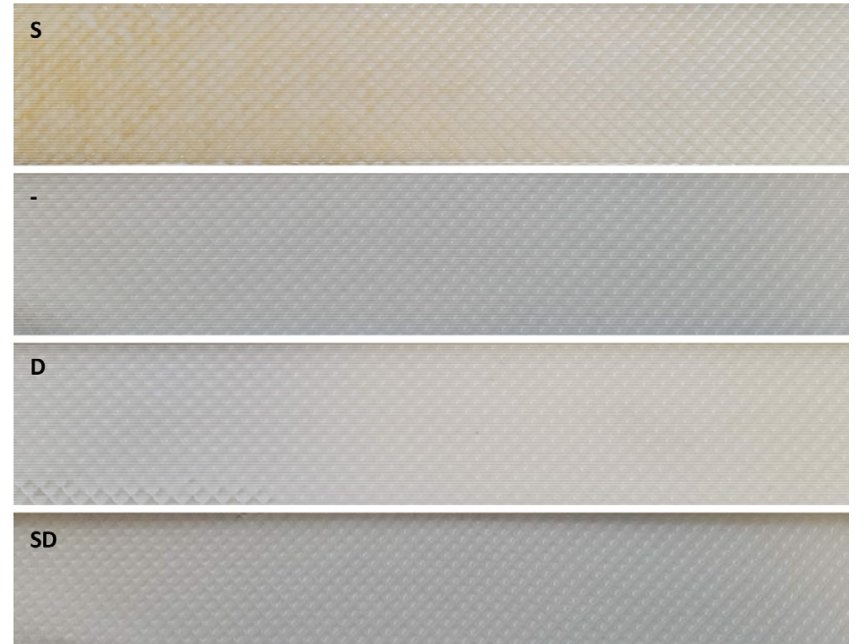

Fig. S2. DBNPA dosage $(1 \mathrm{mg} / \mathrm{L})$ to prevent biofouling. Visual observation of the accumulated material on the membrane and feed spacer in the MFS-units, directly prior sampling for ATP and TOC analysis. S substrate only, - negative control, D DBNPA only and SD. 


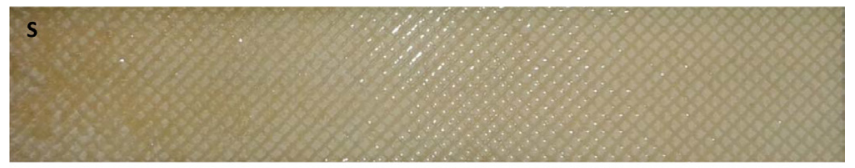

S1
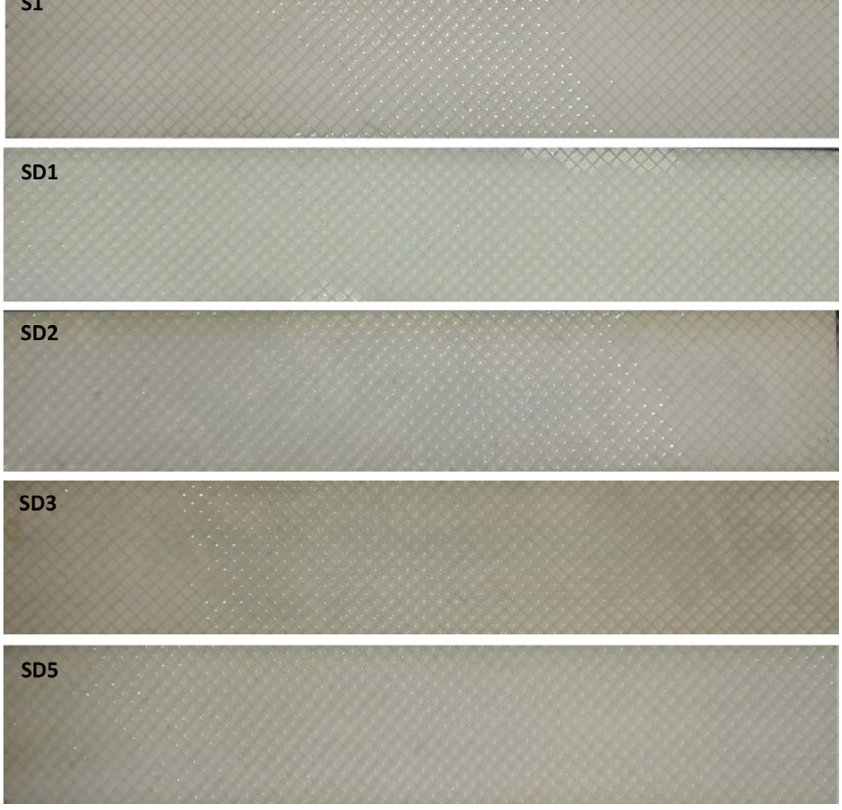

Fig. S3. DBNPA dosage $(1 \mathrm{mg} / \mathrm{L})$ to cure a biofouled membrane system. Visual observation of the accumulated material on the membrane and feed spacer in the MFS-units, directly prior to sampling for ATP and TOC analysis. S positive control, S1, SD1, SD2, SD3 and SD5.

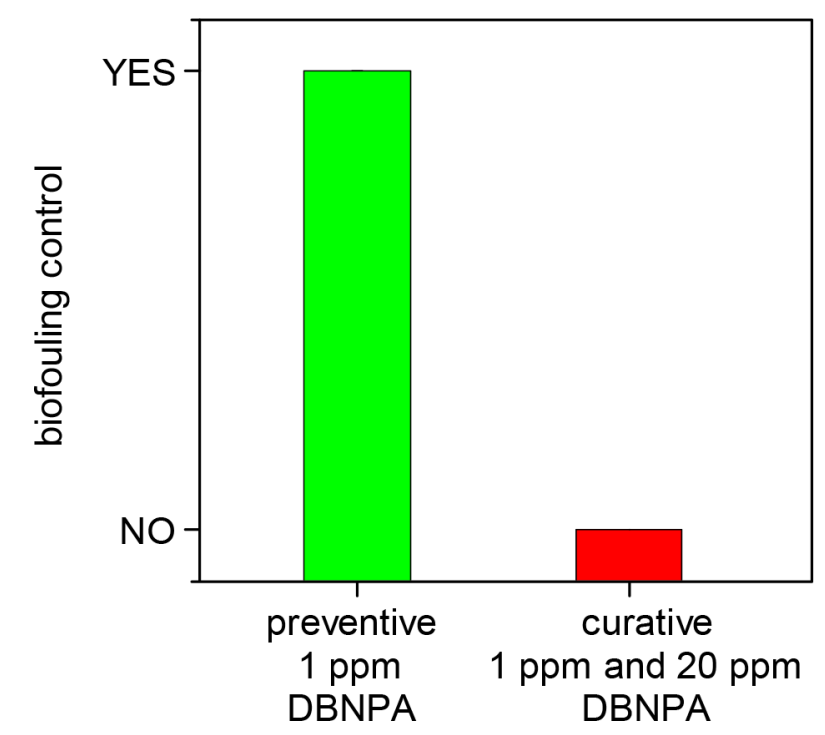

Fig. S5. Graphical abstract: Impact of continuous DBNPA dosage on biofouling control. Prevention of biofouling by continuous 1 $\mathrm{mg} / \mathrm{L}$ DBNPA dosage to feed water with high substrate concentration. No curative biofouling control by continuous 1 and 20 $\mathrm{mg} / \mathrm{L}$ DBNPA dosage.
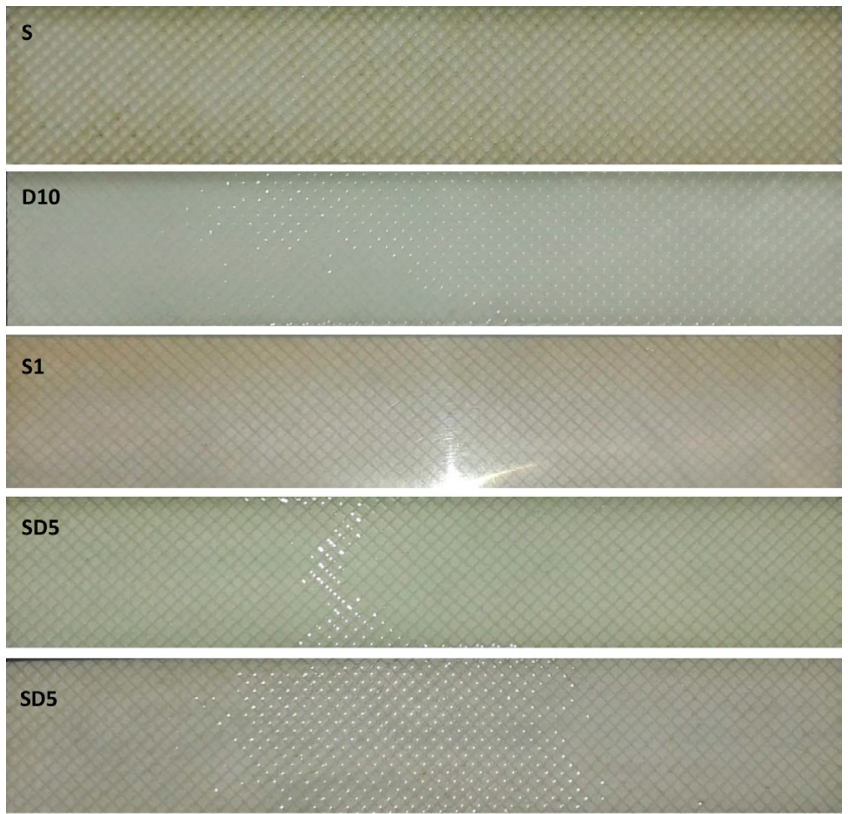

SD5

Fig. S4. DBNPA dosage $(20 \mathrm{mg} / \mathrm{L})$ to cure a biofouled membrane system. Visual observation of the accumulated material on the membrane and feed spacer in the MFS-units, directly prior to sampling for ATP and TOC analysis. $S$ positive control, D10 negative control, S1, and SD5s. 